\title{
LOS DICTADOS (INSALUBRES) EN LAS PASARELAS DE MODA
}

\section{THE DICTATES (UNHEALTHY) IN THE BRIDGES OF FASHION}

\begin{abstract}
AUTOR
David Caldevilla Domínguez: Profesor Doctor en la Universidad Complutense de Madrid. Madrid (España)

davidcaldevilla@ccinf.ucm.es
\end{abstract}

\section{RESUMEN}

La investigación que ha generado este artículo se ha centrado en las características técnicas y generales de las dos principales enfermedades contra las que se lucha, anorexia y bulimia (ya sea para concienciar a la gente que un seguimiento estricto de la moda puede hacer que caigamos en ellas, o para tratar de separar la imagen de la moda de las susodichas enfermedades), y que se cree que la moda ayuda a potenciar (de una forma inconsciente se entiende, la moda no obliga a nadie a ser anoréxico o bulímico).

\section{PALABRAS CLAVE}

Moda - Bulimia - Anorexia - Modistas

\begin{abstract}
The research that has generated this article has focused on the technical and general characteristics of the two main diseases against which we struggle, anorexia and bulimia (either to raise awareness that a strict adherence to fashion can go into a them, or try to separate the fashion image of these diseases), and believed that fashion helps to enpower (in an unconscious way means, fashion does not force anyone to be anorexic or bulimic).
\end{abstract}

\section{KEY WORDS}

Fashion - Bulimia - Anorexia - Dressmakers. 
ÍNDICE

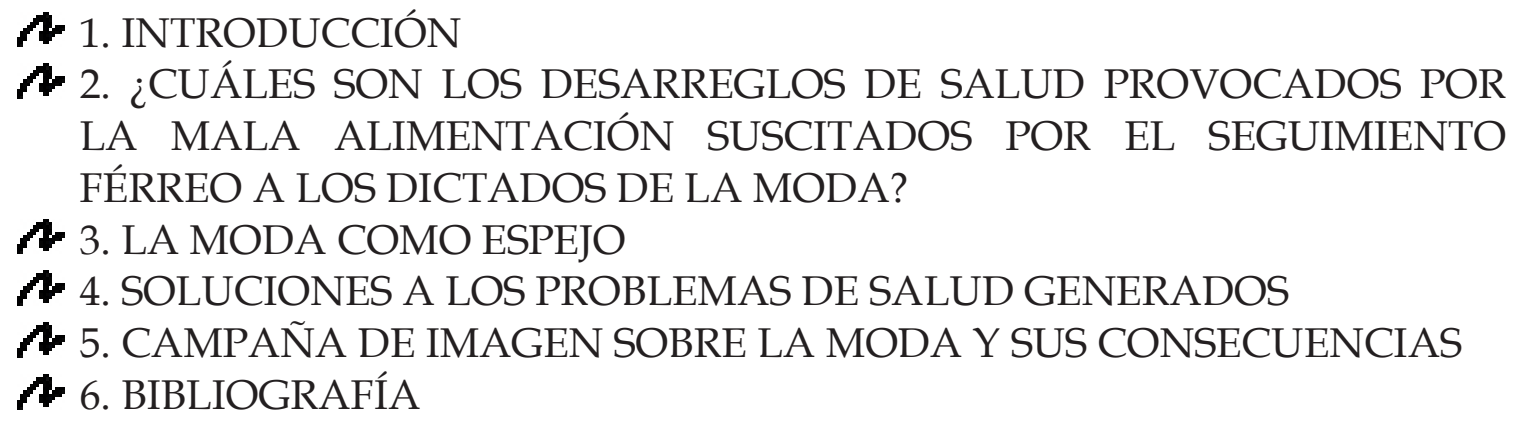

\section{INTRODUCCIÓN}

Desde que la pasarela Cibeles apostara en el mundo de la moda aquello de "belleza sostenible" echando al cubo de la papelera, que es el olvido, las ultradelgadas pasantes con físicos más propios de la desnutrición que del espejo de salubilidad que se pretende de ellas como ejemplo para las nuevas generaciones, los designios de los grandes diseñadores han sido inescrutables.

Con división de opiniones, como las que se suscitan en los ámbitos públicos de amplia notoriedad, los seguidores de las tendencias estilísticas han enjuiciado la conveniencia o necesidad de ver desfilar a mujeres con cuerpo de niñas de una talla 36.

Precisamente esta talla, la mítica 36, es la que tomamos en la Universidad Complutense como "imagen" de la Campaña sobre la moda, como se verá en la imagen de la campaña empleada por la facción anti-dictados de la moda frente a un grupo que defendía los bienes que aporta esta industria millonaria para la sociedad y la imagen que desea reflejar la juventud.

Salud o imagen, imagen o negocio, negocio o salud son los dilemas sobre los que nos vimos abocados a plasmar nuestro análisis que hoy cobra una vigencia fuera de toda duda.

Nuestra investigación se basó en describir qué es la moda y en qué influye en nosotros como consumidores de la imagen que proyecta en la sociedad.

Comencemos por el principio:

\section{2. ¿CUÁlES SON LOS DESARREGLOS DE SALUD PROVOCADOS POR LA MALA ALIMENTACIÓN SUSCITADOS POR EL SEGUIMIENTO FÉRREO A LOS DICTADOS DE LA MODA?}


Empezaremos explicando de una forma muy general en qué consiste la anorexia nerviosa: es una enfermedad que se caracteriza por un miedo intenso a ganar peso y por tener una imagen distorsionada del propio cuerpo, lo que se conoce como dismorfofobia. Quienes la sufren suelen padecer un grave adelgazamiento debido a una dieta exagerada y a un exceso de ejercicio. No se asocia con ninguna otra enfermedad orgánica previa.

La enfermedad produce alteraciones en los ciclos hormonales, una inmunodepresión con aumento del riesgo de infecciones, y aproximadamente entre el 5 y el 18\% de los anoréxicos muere por desnutrición. Suele asociarse con depresiones y baja autoestima.

No existe un tratamiento universal contra la anorexia nerviosa, aunque hay diferentes procedimientos para el tratamiento de pacientes que la sufren y a los que haremos mención más adelante. Para concluir, lo peor de la anorexia nerviosa es que la mayoría de quienes la padecen nunca acuden al médico por lo que no se conoce con exactitud la aparición de la enfermedad.

Por otro lado, la bulimia (enfermedad que aparece en la mayoría de las ocasiones ligada a la anorexia) es un desorden alimenticio causado por la ansiedad y por una preocupación excesiva por el peso corporal y el aspecto físico. Se caracteriza por episodios repetidos de ingesta excesiva seguidos de la provocación del vómito, uso de laxantes, dietas exageradas y/o abuso del ejercicio físico para controlar y perder peso.

La bulimia por sí misma no produce pérdidas importantes de peso, pero siempre está asociada a personas que llevan a cabo dietas exageradas o a enfermos de anorexia, en donde las pérdidas de peso son notorias. Lo que sí produce a veces, debido a los vómitos provocados, son problemas gastrointestinales e hipopotasemias graves, concentraciones bajas de potasio en sangre, así como lesiones en los dientes debido a la acidez de los vómitos.

Para tratar la enfermedad suelen utilizarse los mismos métodos o tratamientos que para la anorexia, que citaremos más adelante.

Tanto una enfermedad como otra, anorexia y bulimia, suelen aparecer sobre todo en adolescentes, especialmente en mujeres, debido a diferentes mecanismos psicológicos, a la dificultad para asumir un cuerpo asexuado, pero el más obvio es la respuesta social a la presión social que valora la delgadez como atractivo físico, algo que la moda y la imagen o modelos que ésta ofrece se encarga de reiterar.

\section{LA MODA COMO ESPEJO}

Especial importancia en la aparición de estas enfermedades la tienen los condicionantes o condicionamientos socioculturales. El tener problemas con la imagen corporal se da 
en una proporción mucho mayor en mujeres, aunque en la actualidad el número de casos masculinos también está creciendo alarmantemente. Y suelen darse en aquellas sociedades donde se enfatiza de una forma exagerada la preocupación por la figura y la delgadez como criterio de belleza, aceptación y éxito social y sexual (y desgraciadamente nuestra sociedad es un ejemplo notorio de ello).

La moda que se nos impone a través de los medios de comunicación para masas, publicidad y otros muchos factores socioculturales, contribuyen a que la delgadez se asocie a prestigio social, sexual, autoestima alta, belleza, elegancia, estar en forma, virtud y búsqueda de perfección, higiene, juventud y facilidad para conquistar. Así la delgadez se ha convertido en un fin en sí mismo.

Los medios de comunicación para masas hacen posible que el mensaje de la delgadez como ideal de belleza llegue a millones de hombres y mujeres a través del cine, televisión, revistas, donde artículos y reportajes sobre métodos y dietas de adelgazamiento invitan directamente a perder peso para tener éxito social y sexual.

Con respecto a la publicidad, de cada cuatro anuncios dirigidos a mujeres uno invita directa o indirectamente a perder peso o a hacer deseable un peso bajo. Además, las mujeres que suelen aparecer en estos anuncios o en las películas, son las más valoradas socialmente, y tomadas como ejemplo a la hora de seguir un adelgazamiento.

La moda se presenta por modelos de dimensiones corporales reducidas, casi esqueléticas, donde además influye la dificultad de encontrar tallas más grandes de la ropa que nos gusta. Es el cuerpo el que se debe adaptarse a la moda, cuando debería ser al revés, porque en éste caso la adaptación nos conduce a la esclavitud.

En los tiempos actuales adquiere una importancia desmedida exhibir el cuerpo que dicta la moda. Dentro del circo de exhibición, los jóvenes caen en una competición estética de la que necesariamente sólo pueden salir o como ganadores o como perdedores, siendo estos últimos "excluidos" de la sociedad.

Por otro lado existe una excesiva exigencia de una imagen determinada para desarrollar ciertos puestos de trabajos, lo que hace que algunas personas, mujeres normalmente, se impongan el cumplimiento del ideal de belleza para poder promocionarse profesionalmente (ejemplos como los de azafatas, vendedoras de grandes almacenes...). El rechazo social del sobrepeso es asociado hoy a desprestigio, donde siempre se alega los riesgos que corre nuestra salud, pero nunca se habla de los riesgos de un infrapeso, que pueden llegar a ser mucho más peligrosos.

Estos fenómenos socioculturales afectan la mayoría de las veces a los adolescentes, especialmente a los chicos y chicas que se encuentran en edades comprendidas entre los 14 y los 22 años, porque se trata de una etapa en la que el cuerpo se está desarrollando y 
cambiando abruptamente, y la imagen que tenemos de nuestro propio cuerpo es más lenta que su evolución biológica.

La responsabilidad recae en la publicidad y en la familia, dos puntos neurálgicos que son a su vez el principal punto de partida para su erradicación. Más si cabe la familia porque es donde se cimienta la educación de los adolescentes, donde hay que admitir la situación, sentirse parte de ella y actuar en consecuencia.

\section{SOLUCIONES A LOS PROBLEMAS DE SALUD GENERADOS}

Una vez se reconoce el problema el siguiente paso es comenzar un tratamiento, y para estas dos enfermedades se conocen diferentes opciones terapéuticas:

GRUPOS DE AUTOAYUDA: tratamiento intensivo ambulatorio y grupal. De gran efectividad.

PSICOEDUCACIÓN: entregar al paciente y a los familiares información detallada del trastorno, de lo puramente orgánico a lo psicológico. A partir de ahí se reeduca al paciente para que salgan de los círculos viciosos "dieta-atracón-dieta", "dieta-purgadieta". Se celebran debates donde se discute el modelo estético actual y se habla del "sep point", el punto de equilibrio del cuerpo con su cuerpo adecuado para mantener la estabilidad.

TERAPIAS DE COMPORTAMIENTO: psicológicas basadas en técnicas activas y directivas. Son diez o quince sesiones donde se da énfasis a la importancia de tener un peso ideal.

\section{$\begin{array}{llll}\text { TERAPIA } & \text { PSICOLÓGICA INDIVIDUAL } & 0 & \text { TRATAMIENTOS }\end{array}$}

FARMACOLÓGICOS, hasta llegar a los casos de mayor gravedad donde sólo se puede recurrir a una cosa.

INTERNACIÓN: los pacientes tienen un peso inferior al 25\% del mínimo acordado para su edad y altura; signos claros de deshidratación moderada o severa, lengua y mucosas secas, hipotensión, taquicardias, lipotimias, desmayos. Y en casos graves, intentos de suicidio. El tratamiento es necesario y consiste en sueros y en observación intensiva por parte de los equipos médicos.

De todas formas lo importante es la información y educación para poder evitar caer en la enfermedad: consultar a un especialista antes de iniciar una dieta (sobre todo si se está en fase de crecimiento); acudir al médico en cuanto se empiece a detectar una perdida desproporcionada de peso; solicitar ayuda psicológica para el enfermo y la familia; comer sano y hacer ejercicio de forma adecuada para que el cuerpo mantenga el peso que necesita. 
Y sobre todo, por encima de todas las cosas, aprender a gustarte tal y como eres para aceptar tu peso ideal.

También estudiamos, desde un punto de vista jurídico las imposiciones de la moda, de la imagen que ésta ofrece, así como la presión social que ejerce la imagen hoy en día. Entiéndase como imagen, aquellos modelos estéticos, masculinos y femeninos, que nos ofrecen las modas para que sirvan como punto de referencia, modelos que son el ejemplo manipulado de éxito y aceptación social.

La complejidad que encierra el tema implica que se estudien áreas tan diversas como los medios de comunicación para masas, la legislación sanitaria, la legislación de la publicidad, la legislación de la moda, el mundo de la estética, la protección de sectores de la sociedad como los niños (infancia), los adolescentes, la mujer, los usuarios, los consumidores, etc.

Aunque las leyes restrictivas de la publicidad puedan parecer a primera vista demasiado duras, nos basta con observar cualquier promoción publicitaria de cualquier tipo de ropa en cualquiera de los medios de comunicación para darnos cuenta de que su incumplimiento está a la orden del día.

Algunas de esas leyes, como por ejemplo la Ley 25/1994, de 12 de Julio, sobre el ejercicio de las actividades de radiodifusión televisiva, declara ilícita en todo caso la publicidad por televisión que fomente comportamientos perjudiciales para la salud o la seguridad de las personas, incluso se prohíbe que la publicidad sugiera propiedades específicas adelgazantes o contra la obesidad, o que pretendan sustituir el régimen de alimentación o nutrición comunes. (Para conocer más leyes de este tipo nos remitimos al informe del departamento jurídico, al enunciado de PUBLICIDAD-SANIDAD, dentro de la LEY GENERAL DE SANIDAD.)

Es evidente que no hay ningún tipo de publicidad que incumpla esta ley, la publicidad de la moda no muestra comportamientos perjudiciales para la salud o seguridad de las personas, a menos de una forma explícita. Pero también es cierto que este control no se traduce en protección, pues los modelos a seguir que presenta este tipo de publicidad de la moda están bastante alejados de la realidad y pretender ser como ello (la única forma de conseguir el éxito con mayúsculas) sí que supone un riesgo para nuestra salud y nuestra seguridad (es muy difícil pretender alcanzar un físico como el de los modelos publicitarios sin poner en riesgo nuestra salud), y contra esto no valen las leyes.

Por un mismo lado, la legislación referente a la protección de ciertos sectores de la población, si bien es cierto que es muy amplia, también es cierto que resulta muy contradictoria. Los planes para promover la moda chocan con las iniciativas para educar a los jóvenes en el consumo; el control que se ejerce sobre la publicidad no sirve para proteger, por ejemplo, a la mujer (que por datos estadísticos es la más afectada por 
este tipo de problemas de salud relacionados con la moda). A pesar de las diferentes leyes, la publicidad suele dar a luz una información defectuosa y una publicidad abusiva, que puede, y de hecho lo hace, dañar a los individuos.

Por otro lado, la legislación referente a la moda propiamente dicha, y no a su publicidad, es igualmente amplia e igualmente incumplida. En este apartado destacamos el desarrollo de un plan social por parte del Ministerio de educación y ciencia en colaboración con el Ministerio de sanidad, Ministerio de trabajo y asuntos sociales, Ministerio de economía y hacienda, y Ministerio de fomento.

Es el Plan Social Contra la Anorexia y la Bulimia, y entre sus muchas recomendaciones destacamos las siguientes: recomienda que se ofrezcan la mayor variedad de tallas posibles en las tiendas, que se utilice una imagen de la mujer más acorde con la realidad. Ambas son claramente desobedecidas, y ejemplos de ello nos los encontramos todos los días en nuestras tiendas o en cualquier tipo de anuncio publicitario.

A pesar de estas recomendaciones incumplidas, el plan también pretende crear un observatorio para la prevención de la anorexia y la bulimia, donde el ciudadano puede llevar a cabo sus denuncias; promover las campañas de prevención e información de anorexia y bulimia, promover campañas dirigidas a los jóvenes que pongan de manifiesto la importancia de una alimentación adecuada, de seguir unos hábitos de vida saludables y de la valoración de la propia auto imagen. Pero todas estas campañas no sirven de mucho si se lucha contra un enemigo tan poderoso como es la moda, más cuando ésta promete a los jóvenes lo que de verdad quieren si la siguen, éxito social y sexual.

Hemos visto, con estos pocos ejemplos como la legislación referente al tema principal de esta investigación sirve de muy poco en la práctica, pero hoy en día la situación es mucho más complicada debido a las oportunidades que ofrece el ciberespacio, es decir, debido a Internet.

Gracias a Internet la oferta de páginas donde se potencia métodos de adelgazamiento, o se genera cierto culto a la anorexia y bulimia entre los adolescentes, han crecido de una forma alarmante. $\mathrm{Y}$ aquí los sistemas de protección y control se ven desbordados, y el número de éxitos no es equiparable al de fracaso (entendiendo como fracaso que el número de páginas que hay colgadas en la red sobre estas enfermedades son muy numerosas).

Los jóvenes pueden acceder desde cualquier terminal a páginas donde chicas y chicos anoréxicos debaten en foros cual es el mejor método para adelgazar sin que te pillen.

En resumen, toda prevención es poca. Si queremos que nadie sufra o ponga en riesgo su salud y seguridad hay que exigir un mejor cumplimiento de la legislación referente a la moda, lo cual no es nada fácil, pues se lucha contra un sector que tiene un volumen de 
negocio desorbitado. Pero el control y protección de la sociedad debe de ser más riguroso para no tener que arrepentirnos en el futuro.

Para completar nuestra investigación, llevamos a cabo una recopilación previa del tratamiento que recibía la moda en los medios de comunicación más relevantes, tanto de prensa como de radio y televisión, para poder así palpar las diferentes tendencias a las que cada medio responde. El objeto de esta investigación previa no es otro que el de poder conocer la línea editorial de cada medio en cuestión para que la segunda parte de la investigación tenga mayores dotes de realismo.

En la segunda parte de la investigación se realiza una simulación de lo que sería una campaña realizada a favor o en contra de una postura relativa al tema. Los medios se encargarán de simular y de interpretar de acuerdo a sus convicciones los hechos que tanto Lobby como Contra-Lobby realizan para cambiar la opinión de las masas. Por tanto, cabe destacar que las noticias creadas en esta segunda parte son totalmente inventadas, siendo fruto de la casualidad cualquier coincidencia con la realidad, y sin que nos hagamos responsables de cualquier opinión vertidas en ellas.

La decisión de realizar una campaña sobre la moda la encontramos todos los días en nuestras calles. Las nuevas tendencias estéticas defienden unos cánones de belleza que pueden llevarse a extremos peligrosos, y hacer peligrar nuestra salud. Los casos de anorexia y bulimia, pues de la prevención de dichas enfermedades causadas o potenciadas por la moda es de lo que trata nuestra campaña, se están convirtiendo prácticamente en una epidemia más de nuestra actual sociedad conformista, que no entiende todavía el peligro que se corre venerando en extremo la perfección física como símbolo de éxito y aceptación social. Estos problemas y su importancia en la actualidad son las principales razones que nos llevan a realizar una investigacióncampaña sobre este tema.

En España el número de casos de este tipo de enfermedades ha aumentado considerablemente en los últimos años, pero aún así la gente no parece tomar conciencia de la situación, entre otras cosas porque se lucha contra un rival muy poderoso, la industria de la moda.

Se está llegando a un punto ciertamente critico en los casos de anorexia y bulimia, que cada vez afectan a adolescentes más jóvenes (sin olvidar que implica también a otros sectores de la población), es decir, se está jugando con la salud de quienes serán nuestro futuro. Y la idea que los jóvenes españoles tienen de futuro no es la correcta, o al menos no es la que se corresponde con la realidad; pues su visión del futuro (una visión que puede aplicarse también al presente), de su ideal a llegar a ser, es una visión tergiversada por la imagen que la moda nos ofrece, una moda que nos dice cómo debemos comportarnos, vestirnos, arreglarnos y cómo debemos ser físicamente para poder ser alguien el día de mañana. Está imagen es reforzada desde los medios de comunicación para masas, que si bien en su parte informativa, entiéndase telediarios o 
programas de salud, nos informa de los peligros de estas enfermedades lo hace sin mucha convicción, pues no es bueno morder la mano que te da de comer, y los medios dependen demasiado de la publicidad de la moda. Sin olvidar los modelos a seguir que las televisiones, en particular, ofrecen a los jóvenes como puntos de referencia para ser alguien importante.

\section{CAMPAÑA DE IMAGEN SOBRE LA MODA Y SUS CONSECUENCIAS}

Tratando de resumir la campaña, comenzamos diciendo que el primer paso es la selección del tema, en este nuestro caso, la moda. Pero el concepto de moda es demasiado amplio y complejo como para querer abarcarlo en una sola investigación. Por eso lo reduciremos a los dictados e imposiciones que marcan el actual canon estético (mujeres y hombres esbeltos, delgados, guapos, dotados de una belleza que se traduce en éxito social y sexual sobre todo), unos dictados que, unidos a la desinformación que desgraciadamente recorre nuestras calles, puede llevar a la gente a poner en peligro su propia salud por la sencilla razón de creer que el atractivo se traduce en aceptación social; entre ellos destacan los adolescentes (sencillamente porque es una etapa en la que se es influenciado desde cualquier frente) pero que también alcanza a más sectores de la población (y para ser realistas, desafortunadamente, a más mujeres que a hombres).

Ahora podemos definir más claramente los objetivos de la campaña, entendiendo que dentro de ésta actúan como agentes principales el Lobby (grupo de presión), y el ContraLobby (grupo de presión que defiende los intereses contrarios al Lobby), a estos hay que añadirles las personas encargadas de representar a los medios de comunicación para masas, así como a una agencia de publicidad (que prácticamente está incluida en el gabinete operativo). Todos ellos trabajan conjuntamente con los resultados de las investigaciones de los cuatro departamentos, a saber: técnico, económico, jurídico y de imagen (claro está que también con sus propias investigaciones).

Los objetivos pues del Lobby serán concienciar al público diana, en este caso particular un público entre 14 y 22 años, de la necesidad de valorarse uno mismo tal y como es, sin añadidos estéticos; concienciarle de la necesidad de romper con las ataduras de la moda, y de informarle acerca de la necesidad de mantener cierto equilibrio para no dañar su salud. Por otro lado, los objetivos del Contra-Lobby son algo más difíciles de definir, debido a lo peliagudo del tema, pues nadie en su sano juicio, ni tan siquiera movido por motivos económicos, defendería la anorexia o la bulimia (principales enfermedades potenciadas por el canon estético actual, y contra las que se lucha en esta campaña), al igual que sucede en otras de nuestras investigaciones donde no se puede defender la pena de muerte por ejemplo. De esta forma, los objetivos del grupo de presión contrario al Lobby, serán defender la moda por encima de las acusaciones de que incitan o potencian las enfermedades antes mencionadas, es decir, alejar la moda de la 
imagen de dichas enfermedades, y defender que la moda también nos ayuda a buscar el equilibrio entre estética y salud.

Durante la investigación se pudo observar que los argumentos sobre la salud eran los más fuertes a la hora de persuadir en contra de la moda y sus dictados. De ahí que los encargados de la Campaña (segunda fase de nuestras investigaciones) enmarcados bajo el epígrafe de Lobby en contra de la "tiranía" de la moda enfocaran sus intenciones al delimitar qué publico objetivo era el más susceptible de aceptar su campaña frente al otro grupo, defensor a ultranza de la moda (llamado Contra-Lobby).

La primera tarea que tiene que llevar a cabo el gabinete operativo del Lobby es la selección del público objetivo, como diana a la cual está dirigida la campaña. El grupo decidió que este público objetivo lo formarían los jóvenes comprendidos entre los 14 y los 25 años porque es el segmento de la población que más sufre las consecuencias de los problemas derivados del seguimiento estricto de los dictados impuestos por la moda.

El siguiente paso es celebrar reuniones para comenzar con la campaña. A estas reuniones acuden los miembros del gabinete operativo que son, o al menos deben serlo: todos los miembros de la agencia de publicidad, dos miembros de cada uno de los cuatro departamentos, y dos seguidores por medio que se encargaran de informar al resto de seguidores (aunque siempre puede haber más en el gabinete, pero lo mínimo es dos por medio).

Más concretamente se llevaron a cabo tres reuniones oficiales que pasamos a detallar a continuación:

En la primera reunión se sacaron las siguientes conclusiones, el tema propuesto sería "La moda y sus dictados", el objetivo de la campaña que sería concienciar al público de la necesidad de la diversidad frente a la moda; la determinación del target que ya explicamos anteriormente. Se propuso crear una plataforma como estandarte de la campaña, que además llevaría el lema "Damos la talla".

-En la segunda reunión se profundiza un poco más: se concreto que el inicio de la campaña tendría lugar el día 12 de Agosto, correspondiendo con el día mundial de la juventud, aunque los primeros pistoletazos de la campaña (como la aparición de los anuncios en televisión y radio) se adelantaría al 2 de Agosto. Se eligió el nombre de la plataforma, "36 y más", por su vinculación a la talla que usan como referencia los creadores de la moda. La agencia de publicidad presenta los primeros bocetos en coordinación con el departamento de imagen y también los primeros guiones para los anuncios publicitarios, así como las diferentes localizaciones exteriores para su realización. Se dan las primeras instrucciones a los seguidores para que comiencen a negociar con los dueños de los medios. La elección de los medios con los que se 
trabajará de determina gracias a un informe de una agencia de estudios sociológicos y de audiencias contratada.

-En la tercera reunión se fija una hoja de ruta definitiva: Una vez rodados los anuncios publicitarios, son aprobados por el gabinete y determinan los diferentes horarios en los que se intentará emitir los mismos (para lo cual los seguidores deben negociar con los dueños de los medios) basándose en datos de audiencias. Se fijan tres eventos y acontecimientos importantes como puntos clave en el desarrollo de la campaña; el 12 de Agosto se celebra un macroconcierto en el palacio Vistalegre (Madrid) por la diversidad donde participarán diferentes artistas; el 8 de Septiembre se organiza un partido benéfico en el estadio Vicente Calderón patrocinado por la plataforma "36 y más" entre un combinado mixto nacional y un combinado mixto internacional; y por último el 16 de Octubre, con motivo del día mundial de la alimentación se celebrará en el parque del Retiro un gigantesco Happening con multitud de actividades destinadas a todos los públicos, desde juegos para niños hasta charlas y coloquios para informar a las personas preocupadas por las enfermedades relacionadas con la alimentación. Está patrocinado por la conserjería de asuntos sociales del excelentísimo Ayuntamiento de Madrid.

Además se aprobó la publicidad a utilizar en marquesinas y autobuses, y se fijo el día 2 de Agosto para celebrar una rueda de prensa donde el director de la plataforma y dos artistas invitados, que participan en el macroconcierto, informan del porqué de la celebración de dicho concierto y su participación en él.

Ésta es la parte de la que se encarga el gabinete operativo, que es más que nada un gabinete de decisión, pues la realización práctica de los puntos citados anteriormente la llevan a cabo la agencia de publicidad y los seguidores de los medios cuya actividad detallaremos a continuación.

La camiseta de la Campaña fue ésta: 


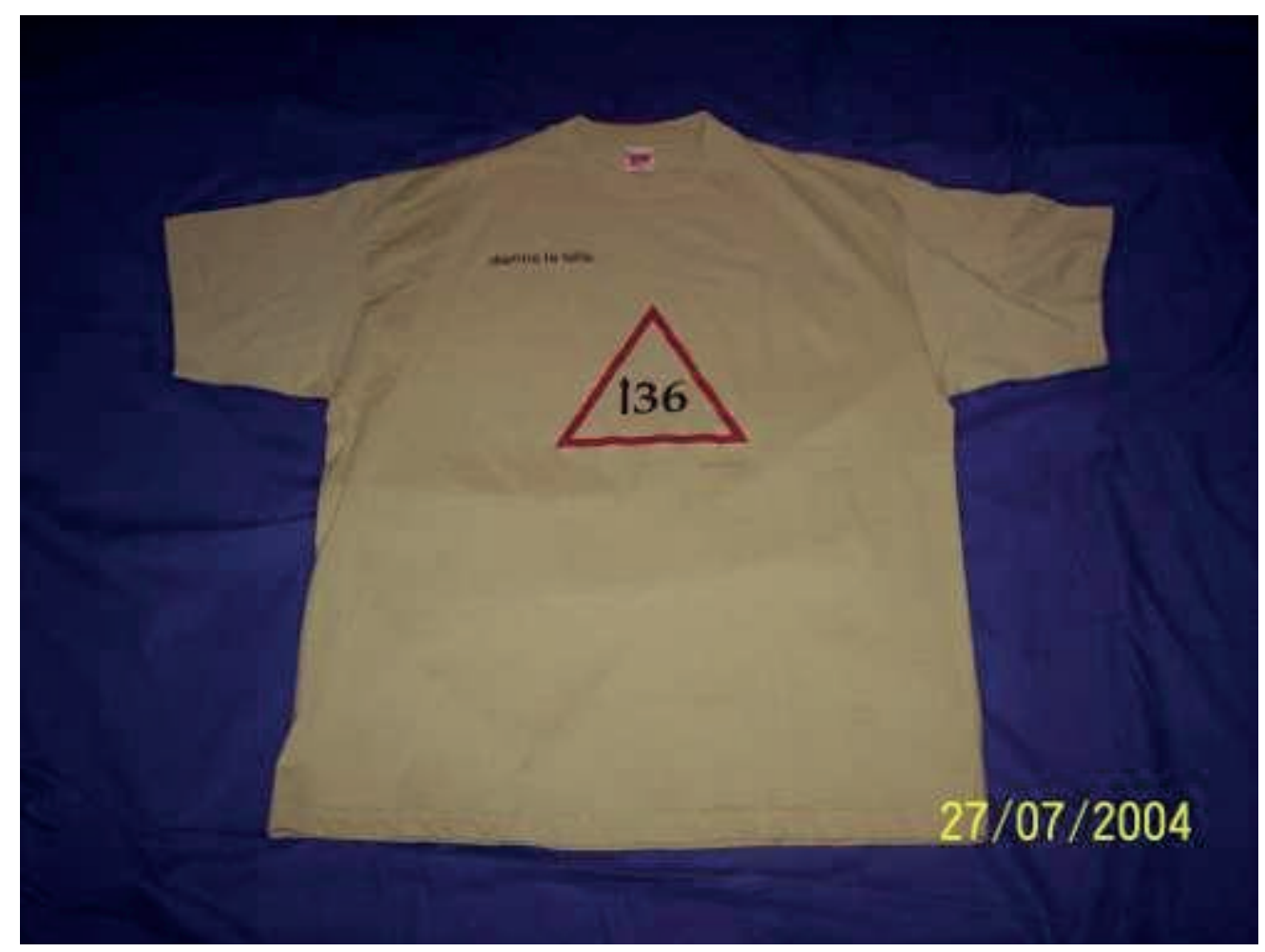

Por otra parte, el Contra-Lobby tiene como primera tarea solventar las trabas éticas y morales que supone defender la imagen de la moda. El grupo de presión decidió defender la imagen de la moda como una búsqueda del equilibrio estético y saludable.

Para defender este objetivo crearon una plataforma de nuevos creadores por la moda, la cultura y la belleza, y le dieron el nombre de plataforma "Estoy de Moda", como fenómeno cultural, defendiendo la búsqueda del equilibrio corporal y mental.

La campaña la estructuraron en dos líneas principales: una primera enfocada a un público objetivo joven, que quiere vestir para realzar y traducir su mundo interior. El lema "¡Estoy de moda!" traduce esta línea haciendo que se corresponda con la parte más explícita de la campaña, pues representa la moda a través de una perspectiva cultural y como la solución a la búsqueda de identidad de los más jóvenes.

Y una segunda línea que tiene una mayor base informativa y por lo tanto, es menos directa. Esta línea busca que la belleza se traduzca en equilibrio y que la moda no sea únicamente un atuendo sino un estilo de vida que haga sentirse bien al individuo, por dentro y por fuera. El lema que defiende esta vía es " Necesitas equilibrio!".

Dentro de los principales acontecimientos ideados por el Contra-Lobby como puntos de referencia en la campaña destaca la celebración de un concierto y diversos actos conmemorativos en relación con el día mundial de la moda, cultura y belleza, que tiene lugar el 1 de Agosto. Este se celebrará además en Barcelona dentro del marco cultural creado por el Forum 2004, y contará con la participación de diferentes artistas de gran 
variedad que defienden en sus personas la modernidad, la vanguardia, el gusto por la moda y el cuidado de la salud (para conocer más detallada mente quienes son lo artistas invitados me remito al informe del Contra-Lobby).

Además, se pondrá en el mercado un disco recopilatorio del concierto que podrá ser adquirido gratuitamente en la sede de la plataforma o a partir del 3 de Agosto por la compra de cualquier producto de los patrocinadores de la campaña.

También destaca la celebración de una serie de cursos, seminarios y conferencias para promover las cualidades de la moda como expresión artística de gran repercusión social y como invitación al cuidado físico. La plataforma se ha acercado a los ámbitos educativos y culturales para llevarlos a cabo contando con la colaboración de diferentes universidades así como del Forum de Barcelona. Para más información acerca de quienes imparten los cursos y el lugar de celebración de los mismos me remito al informe del Contra-Lobby.

Un punto a destacar del Contra-Lobby es su acercamiento a las nuevas tecnologías mediante la creación de un portal web donde presenta información de la plataforma la campaña que desarrolla, así como los objetivos que persigue e información de sus patrocinadores. El portal, www.voguis.com, puede visualizarse en el informe del Contra-Lobby.

En lo que ellos mismos denominan como campaña informativa llevan a cabo el desarrollo de la publicidad las negociaciones con los dueños de los medios. En el Contra-Lobby, como es un grupo mucho más reducido no hay subdivisiones entre los miembros y se les deja que actúen por su cuenta, repartiéndose el trabajo como ellos consideren necesarios.

Se desarrollaron una serie de publirreportajes que van a difundirse en semanales de prensa escrita, entre los que destacan algunos referidos a la belleza, salud y moda, o a las nuevas tendencias estéticas de los hombres, el metrosexual; además de una serie de noticias acerca de los riesgos de la obesidad y su gato sanitario. El despliegue de noticias y reportajes será intensivo entre los meses de Julio y Septiembre, para crear una conciencia general en torno al día internacional de la Moda.

El desarrollo de la publicidad se ha dividido en función de los diferentes medios con los que han trabajado.

En lo referente a prensa escrita los principales periódicos con los que se han trabajado son: EL PAÍS, LA VANGUARDIA, EL MUNDO, ABC y LA RAZÓN. Estos medios disponen de dos tipos de publicidad en función de las dos líneas que sigue la campaña. La primera línea, explícita sobre la moda como elemento para la interpretación del mundo interior, ha sido la más desarrollada por la plataforma por ser más directa y más cercana al target. Consiste en presentar durante el primer mes de campaña, Julio, un 
cuadro clásico de la pintura española y durante los dos meses siguiente de campaña, Agosto y Septiembre, la visualización de los mismos, mostrando cinco estilos diferentes de moda, actualizándoles a la época actual; siempre acompañados del lema: ¡Estoy de moda! o ¡Estamos de moda! dependiendo del número personajes que participen en el cuadro.

Los cuadros seleccionados son "Las señoritas de la calle Avignon" de Picasso, "la muchacha de la ventana" de Dalí, "La Venus de espejo" de Velázquez, "El quitasol" de Goya, y "Carlos III de niño" de Rana. Se ha intentado que cada periódico se identifique con dos de los cuadros seleccionados y que se publiquen los viernes y los domingos de acuerdo con la ideología del mismo. Se pretende buscar el equilibrio entre los lectores del medio y el contexto que va a acompañar al anuncio.

Por otro lado la segunda vía se trata de trasladar la relación entre belleza y salud de forma gráfica, apoyándose en los argumentos de la Organización Mundial de la Salud y reforzada con el lema "Necesitas equilibrio" (representado a través de una balanza).

En lo referente a televisión, los anuncios grabados por la plataforma son dos y hacen referencia a la vía principal de la campaña, con el lema: "Estoy de moda". Estos anuncios recrean la idea de los anuncios gráficos, trasladando también cuadros clásicos al día de hoy. Los cuadros elegidos son "Los Borrachos" de Velásquez y "La maja desnuda" de Goya, donde partiendo de las imágenes del cuadro se intercalan imágenes de la actualización de la obra. Sólo se mantuvo relaciones con Telemadrid, Telecinco, Antena 3 y Canal +, y las especificaciones de los horarios de emisión se encuentran detalladas en el informe del Contra-Lobby.

Por otro lado, la radio tiene e el Contra-Lobby una mayor importancia, pues se llegaron a realizar cinco cuñas radiofónicas. En este medio se ha querido hacer hincapié en la vía "Necesitas equilibrio" porque la plataforma ha considerado que es un lema mucho más sugestivo para el medio radiofónico (caracterizado por la modulaciones de la voz). Para escucharlas y comprender un poco mejor la labor a desempañar por las cuñas me remito a los archivos de sonido del Contra-Lobby. Se trabajó cono COPE, SER y ONDA CERO.

Además la plataforma concedió una entrevista en exclusiva a ONDA CERO con motivo del día Internacional de la Moda, la Cultura y la Belleza, el 1 de Agosto para el programa "Protagonistas" (podrá escucharse en formato mp3 en el portal web.

Y por último la publicidad exterior, considerada por la plataforma como primordial, pues no sólo quiere llegar al público objetivo, quiere estar presente allí donde exista la personalidad individual, la moda y el respeto a la salud. Por este motivo cree importante hacer una campaña de publicidad exterior exhaustiva y diversificarla en distintos anuncios gráficos. 
Balanza "Necesitas equilibrio", se va a utilizar en publicidad exterior de disposición vertical, sobre todo en las marquesinas del suburbano.

Diseño "Plataforma Estoy de moda", se va a utilizar en publicidad exterior para marquesinas. Además, debido a su colorido y por contar con la imagen femenina de la campaña y la dirección de la plataforma, se ha decidido que va a ser el diseño utilizado para elaborar postales de difusión gratuita, gracias a un convenio con la empresa Postal Free.

Diseño "Estoy de moda" en disposición horizontal, como anuncio fuerte en publicidad exterior. Se pretende que aparezca en vallas publicitarias, marquesinas, transporte público y cabinas telefónicas, y en todos los espacios posibles pues este diseño engloba la idea general que tiene la plataforma sobre la moda y cuenta con la imagen femenina de la campaña (actualización del cuadro "Las Meninas" de Velásquez).

En resumen, y para finalizar las conclusiones podemos afirmar que los objetivos perseguidos por el Contra-Lobby serán fácilmente alcanzados debido a la simpática conexión que logra con el público gracias a la actualización de los cuadros clásicos. Además ha sabido resolver sin problemas un problema tan peligroso como es el que asociaran su imagen con la invitación directa o indirecta a perder peso (como es la que logra la moda actual); lo resuelve poniendo en relación la moda, la cultura y la salud, la búsqueda de una identidad estética no tiene porque chocar con la pérdida del equilibrio de la salud; son cosas que pueden combinarse perfectamente siempre que se esté bien informado, algo que pretende el Contra-Lobby, informar de las posibilidades de la moda y hacer entender a la gente que la moda no crea los problemas a la gente, sino al contrario, puede ayudar a solucionarlos.

En definitiva, nunca hay que separar la imagen de la moda de la imagen de equilibrio, y eso es lo que intenta hacernos comprender el Contra-Lobby.

La camiseta promocional de su Campaña fue ésta: 


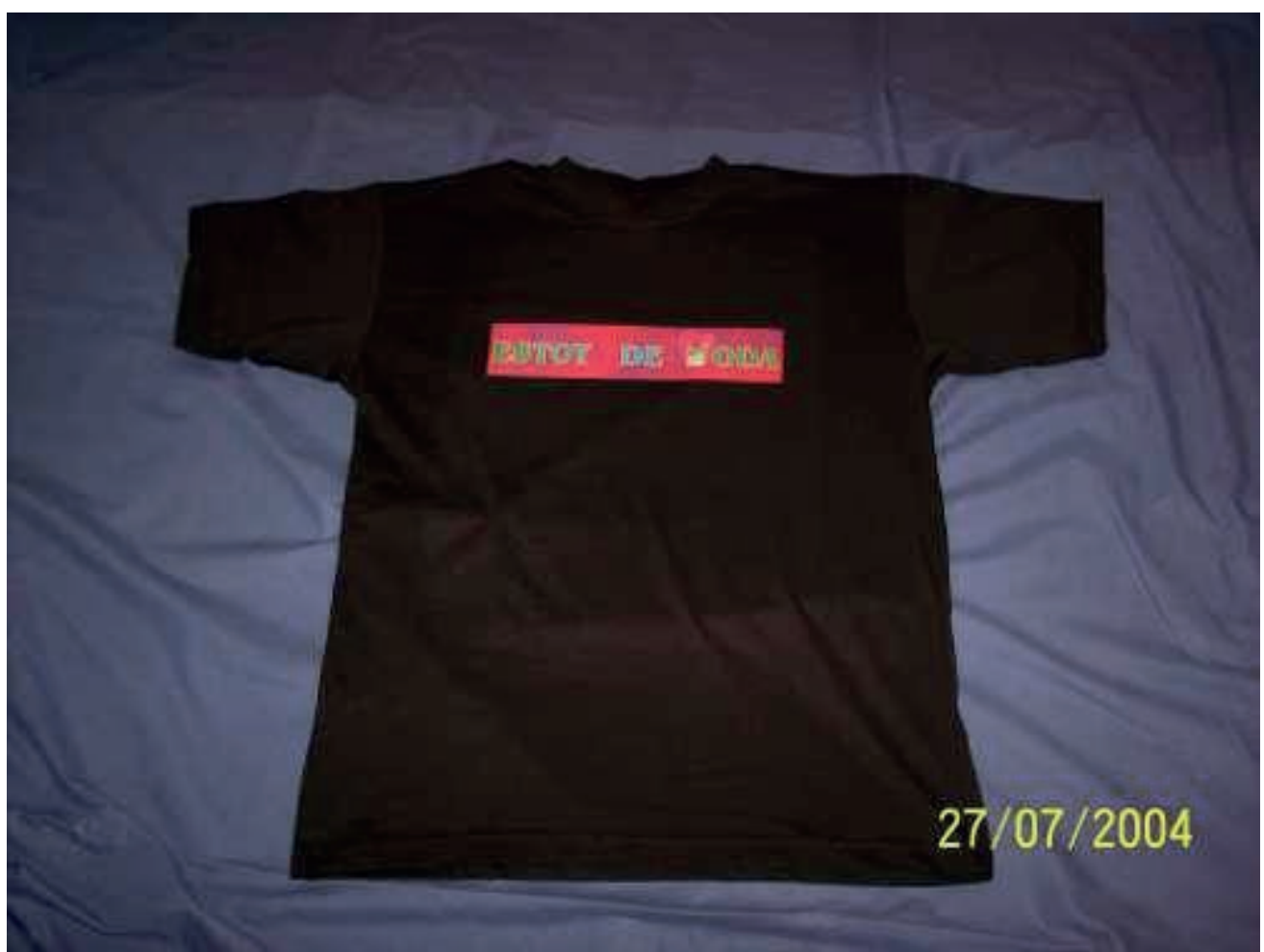

Y ésta la campaña publicitaria y promocional en los Medios de Comunicación para Masas:
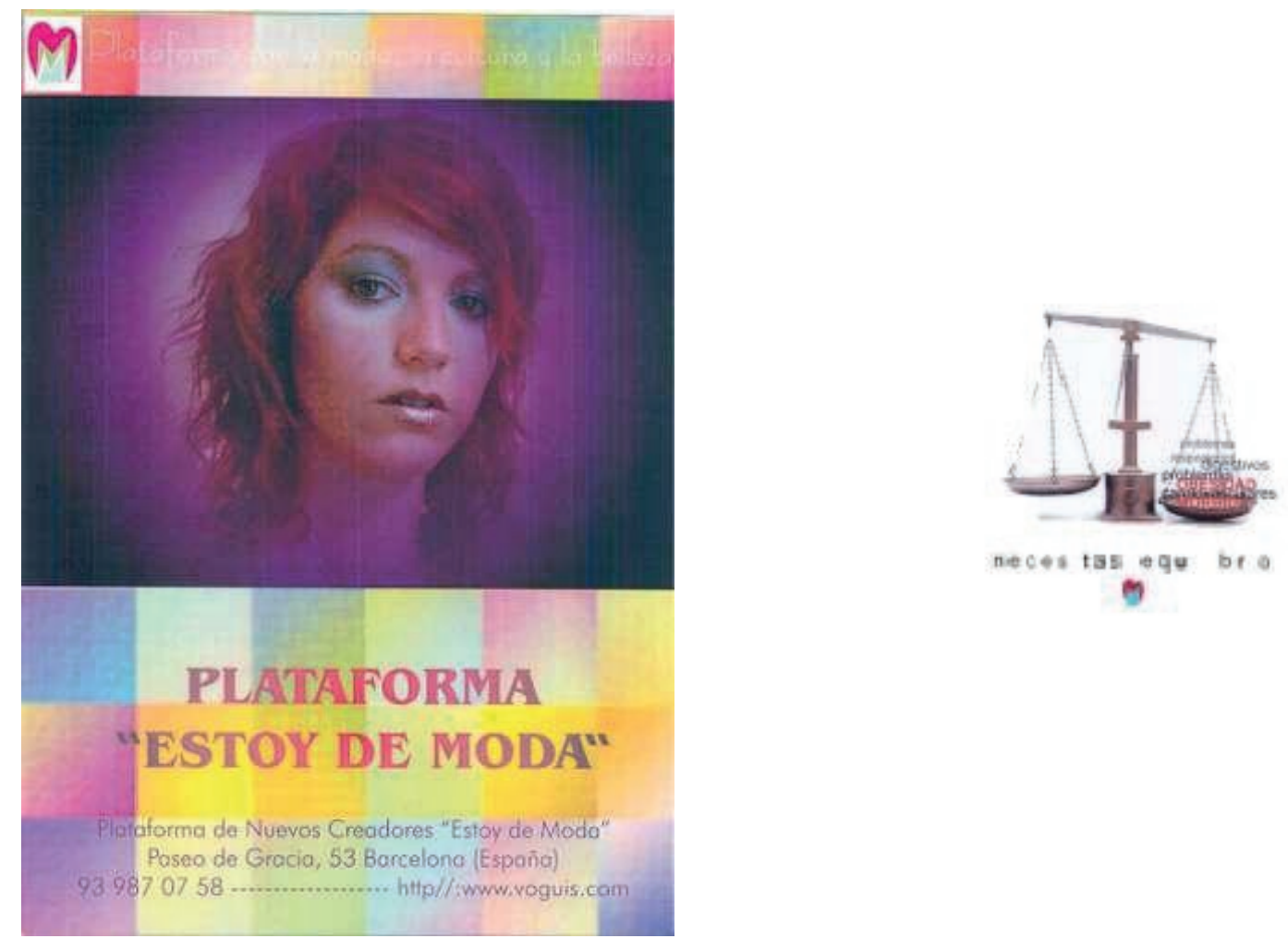

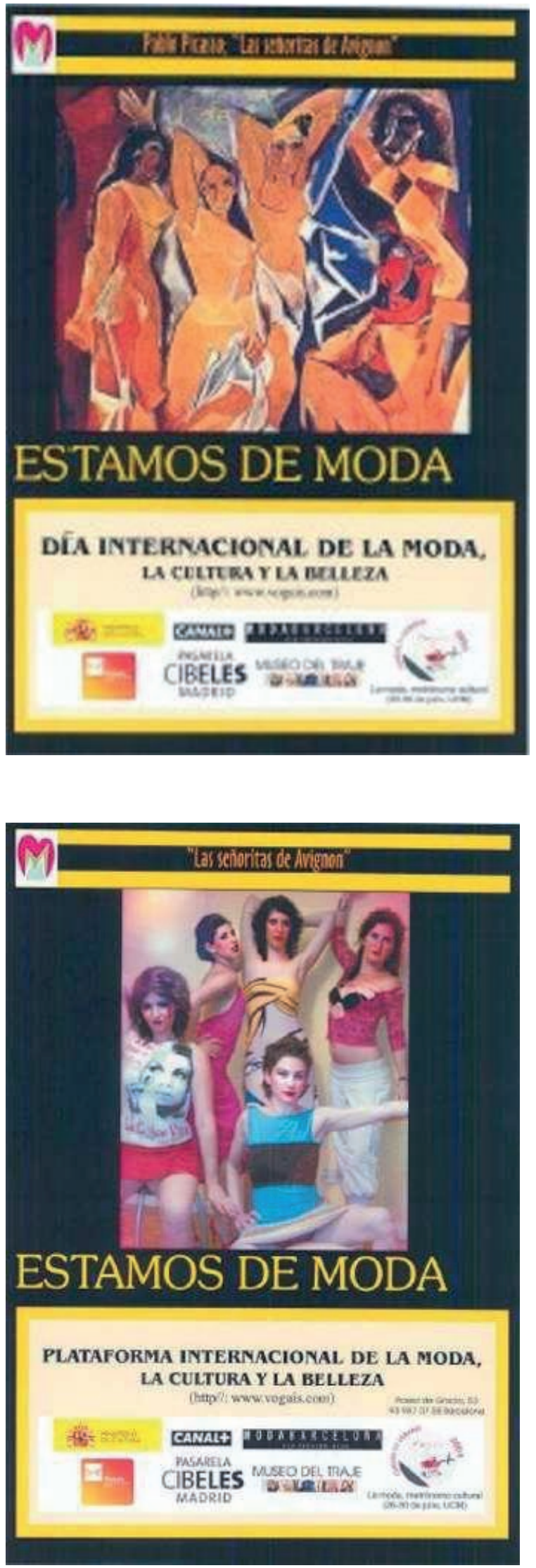

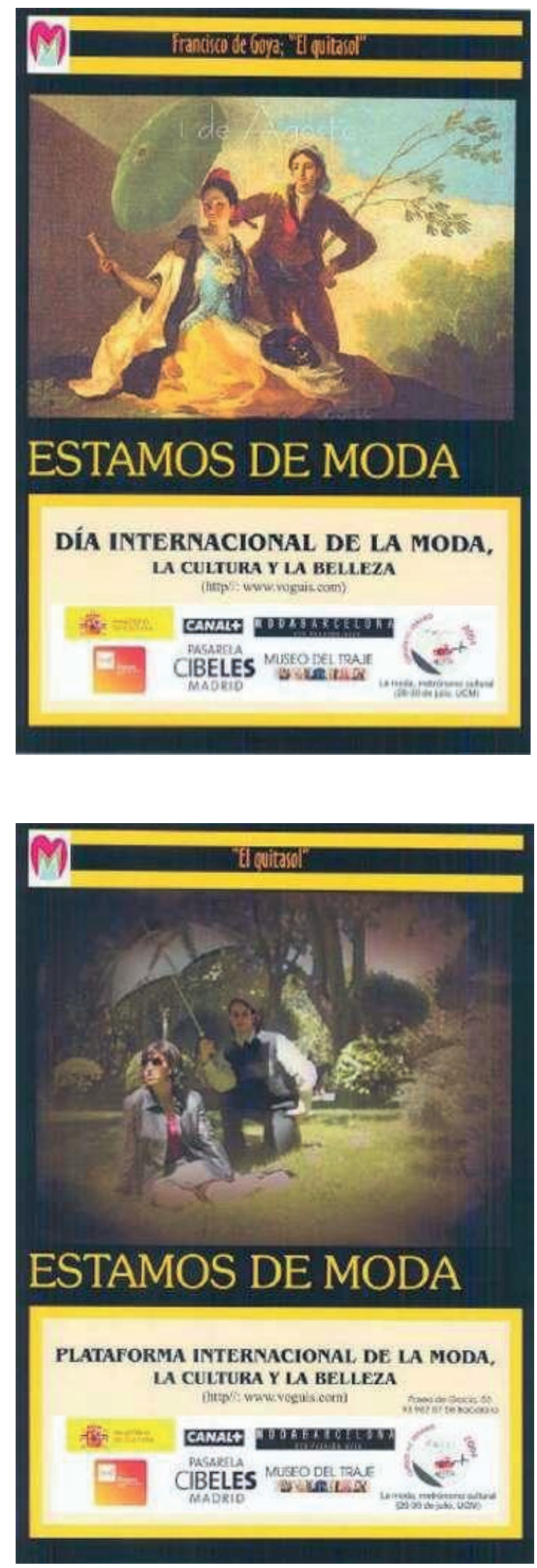

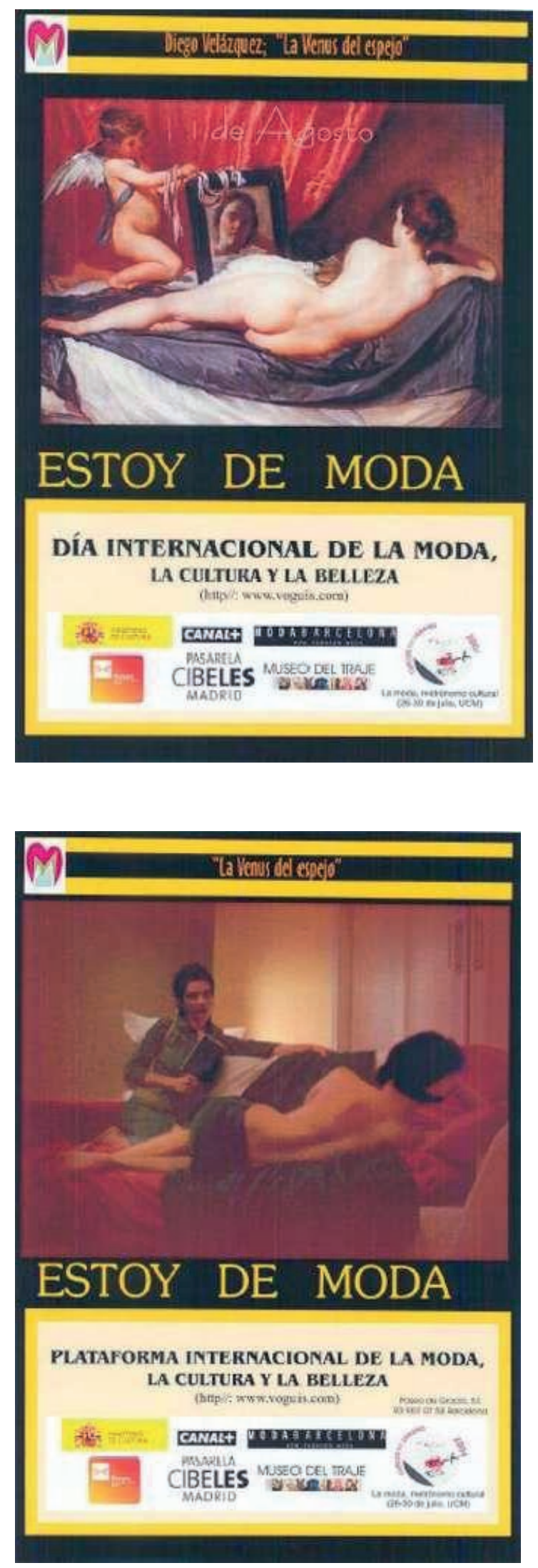

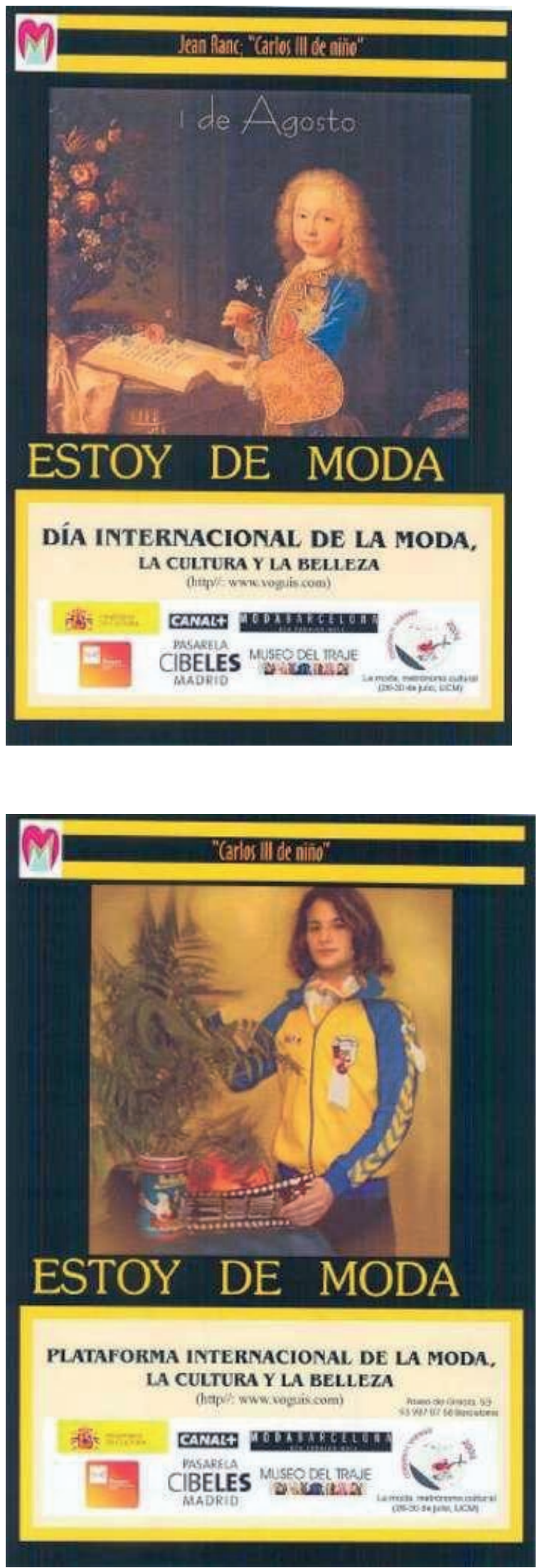


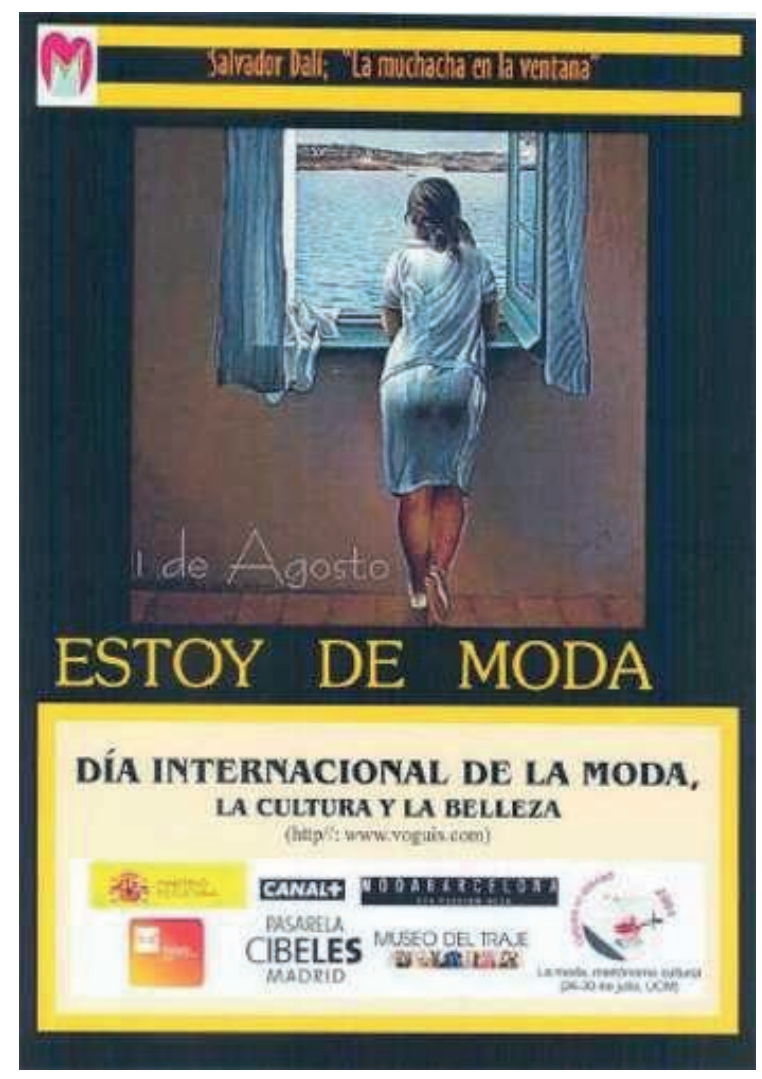



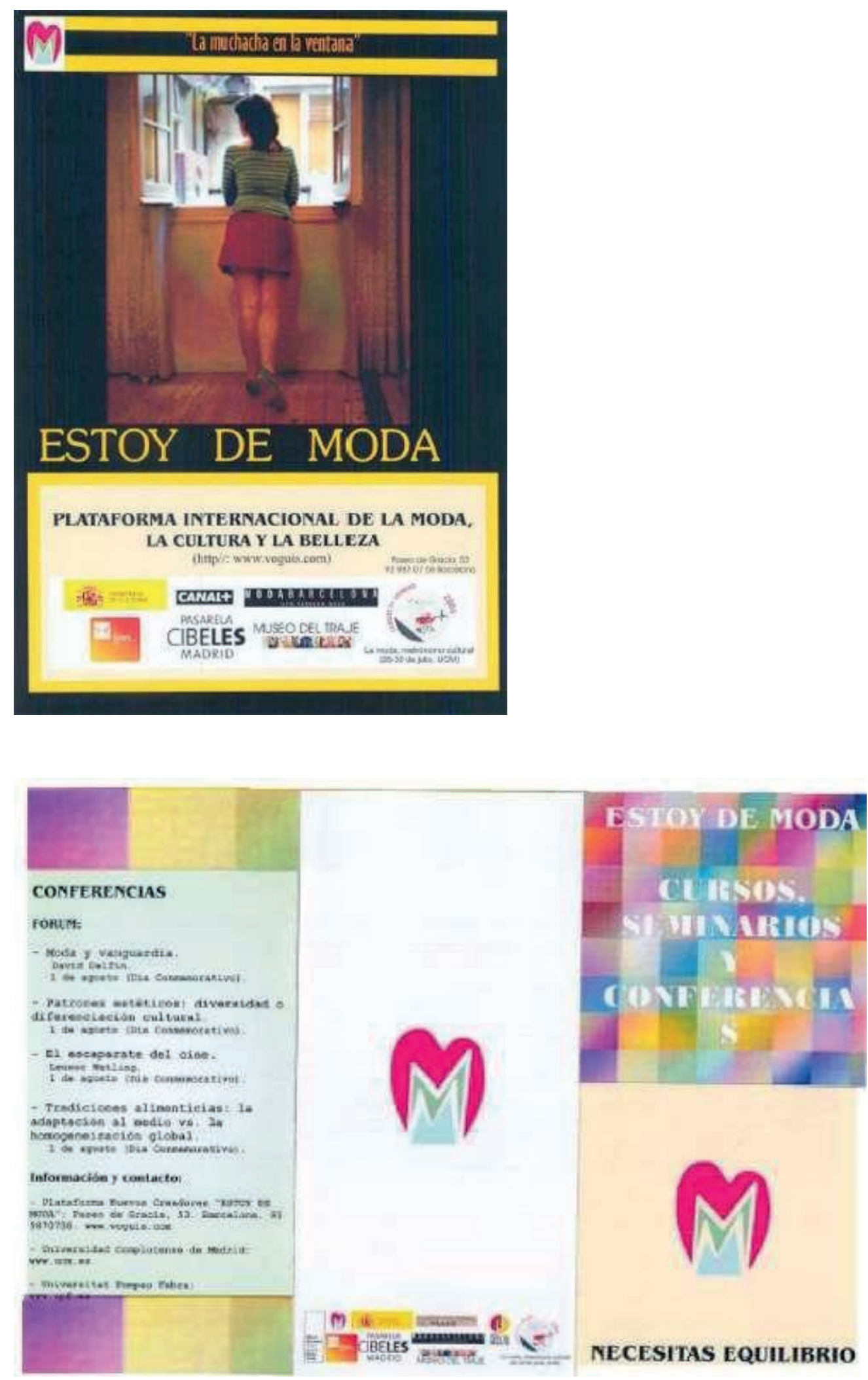


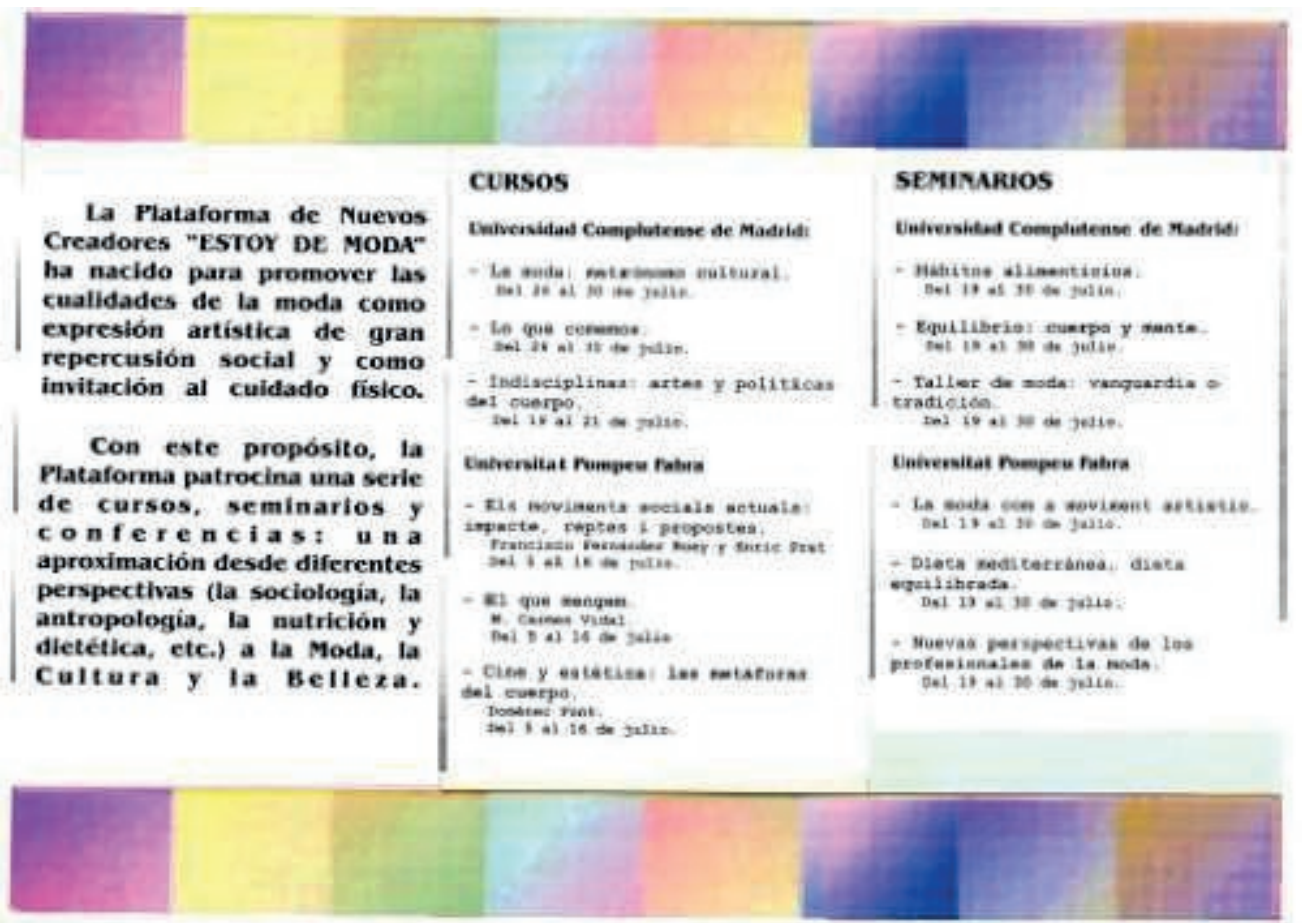

Los anuncios en prensa se basaban en el concepto de romper con la talla 36 como símbolo de lo que no debe ser la moda. Lo hicieron de esta manera:

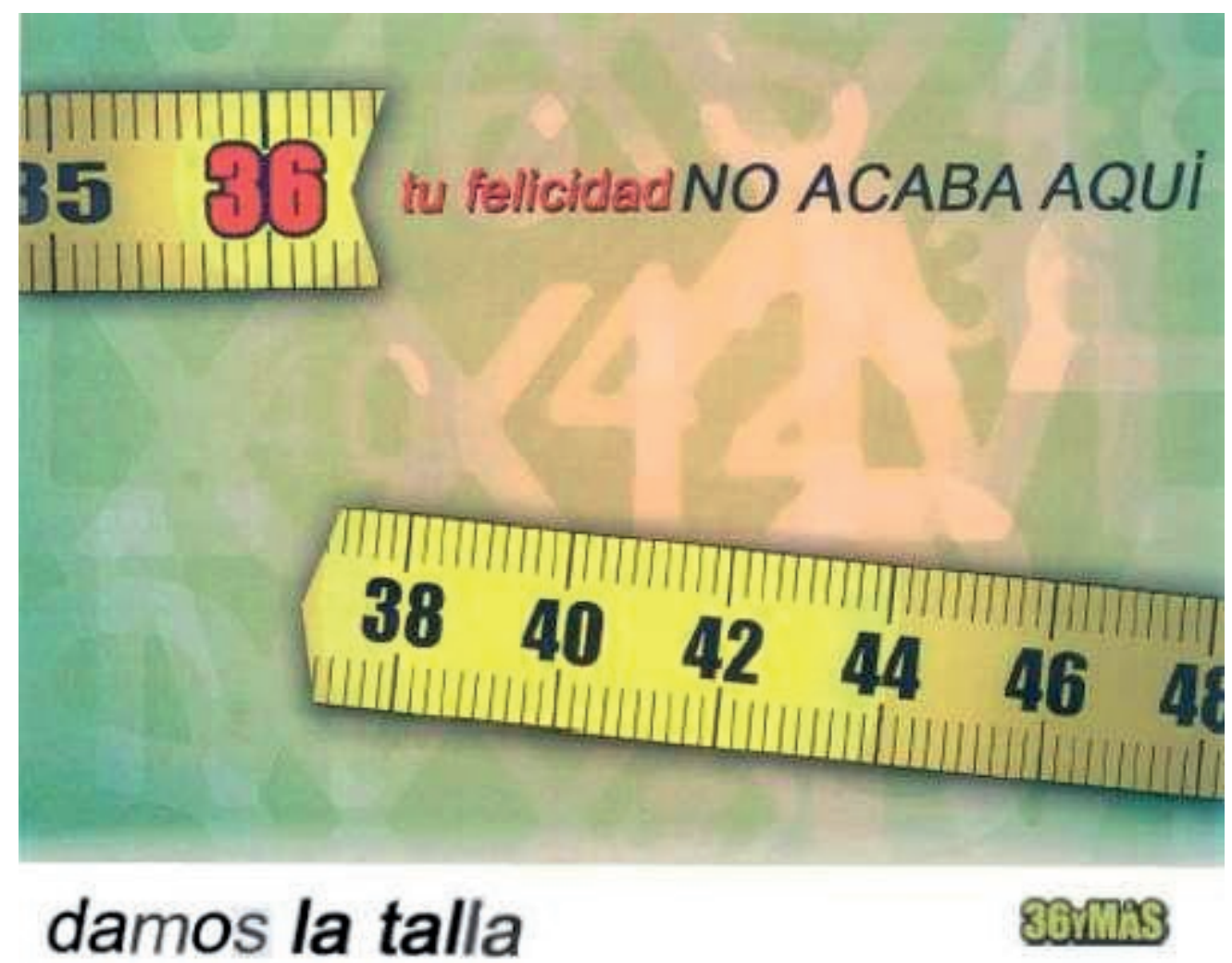

Y, entre otros, éste: 


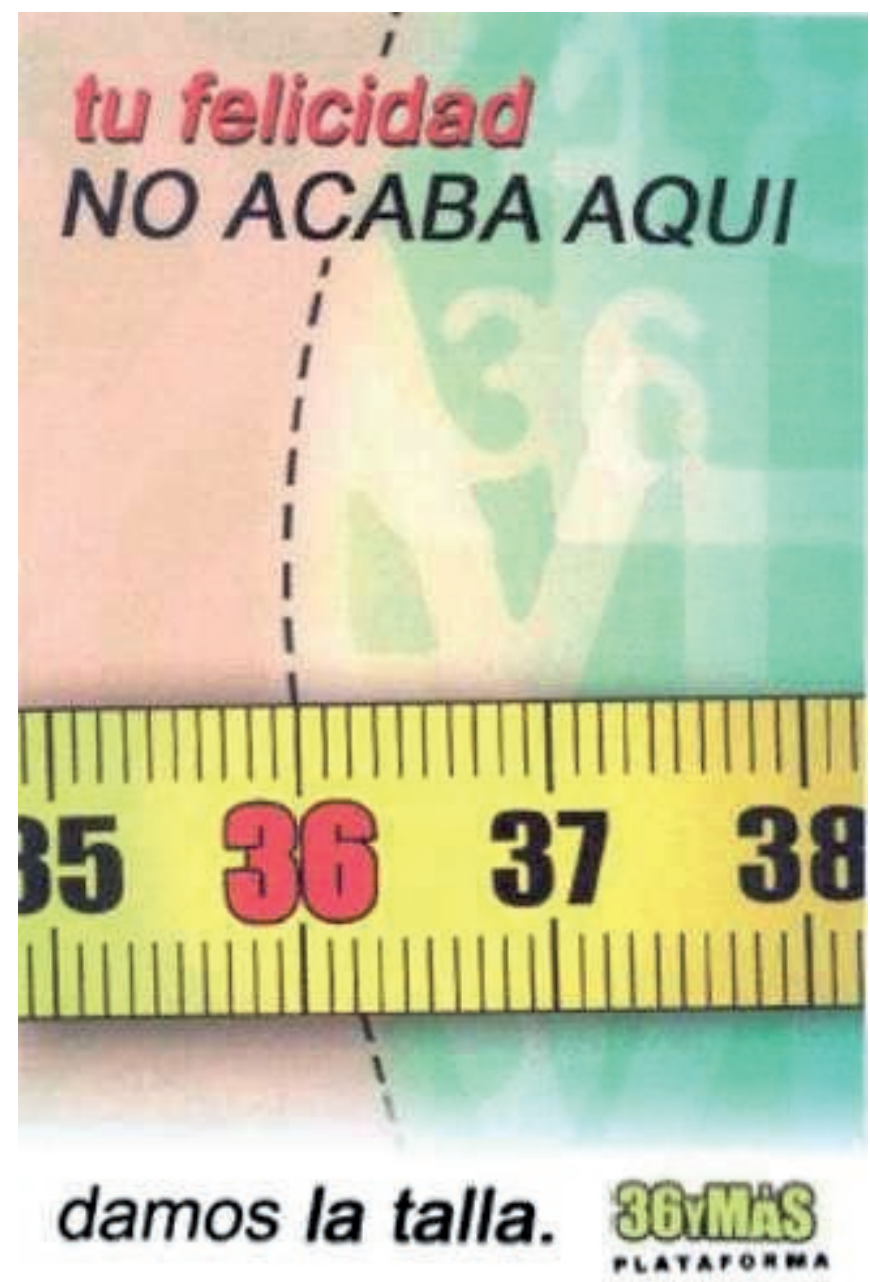

Como se ha podido comprobar las campañas iban a sacar a la Opinión Pública de su estado de letargo al respecto del tema.

Para muestra véase el análisis y desarrollo de la campaña planteados por el Lobby:

El objetivo de la campaña: Concienciar al público objetivo de la necesidad de la diversidad frente a la moda.

La campaña estaría orientada hacia un público objetivo de 14 a 25 años debido a que es el segmento de población que más sufre las consecuencias del problema de los dictados de los modistos y de las casas comerciales de moda.

Se propusieron varios nombres sugeridos por la Agencia de Publicidad para la Campaña fincando al final el lema "Damos la talla".

Se propuso crear una plataforma cívica que diera coherencia a la Campaña.

Se le da la orden a los seguidores de los Medios de Comunicación para Masas para que comiencen a sondear los posibles soportes. 
Se concretó el final y el principio de la campaña. Se eligió el día 12 de Agosto, día mundial de la juventud como comienzo de los actos de la campaña, aunque retrasaríamos esa fecha después al 2 de Agosto.

Para el final de la campaña se designó el día 16 de octubre, día mundial de la alimentación.

Se eligió el nombre de la plataforma y, tras barajar distintos nombres, quedó como definitivo el de "36 y Más" por su vinculación a la talla que usan como referencia los creadores de moda y que llevan por los caminos de la amargura a las adolescentes y no tan adolescentes de hoy en día.

Se mostraron bocetos de la Agencia de publicidad de la campaña gráfica siendo debidamente corregidos por el departamento de Imagen y aceptados aquellos que eran acordes. Se propusieron los guiones de rodaje u grabación de los anuncios televisivos así como de las cuñas radiofónicas. Siendo aprobadas por el gabinete.

Se montan por parte de la Agencia de Publicidad los primeros anuncios y cuñas, designándolos como "Pasarela urbana".

Los seguidores de los medios reciben las órdenes de negociar con los medios elegidos gracias a un informe de una agencia de estudios sociológicos y de audiencias contratado. Se negocia con todos los Medios de Comunicación para Masas.

Hoja de ruta: Una vez montados y exportados al soporte necesario, el gabinete operativo supervisó los anuncios, dando el visto bueno. Se analizaron los datos de audiencia y se fijó la ubicación de los anuncios en los medios los días que se pensaron convenientes que más a delante detallaremos.

\section{Se fijaron cuatro eventos fundamentales:}

12 de agosto, el macroconcierto por la diversidad; se acordó contratar a los artistas musicales para que ofrecieran un concierto a bajo precio en la plaza de toros multiusos Vistalegre (Madrid).

16 de Agosto, Contratamos a una modelo que se desmayará durante una gala de verano de TVE, el suceso será carnaza para los medios durante esa semana.

8 de Septiembre, Se organiza un partido de fútbol benéfico en el estadio Vicente Calderón patrocinado por la plataforma. 
16 de Octubre, con motivo del día mundial de la alimentación convertiremos el parque del Retiro en un gigantesco Happenning con multitud de actividades diversas patrocinado por la consejería de asuntos sociales del Excmo. Ayuntamiento de Madrid.

Se comienza a emplear el uso de publicidad en marquesinas y autobuses después del suceso de la modelo.

Se fijó como comienzo de la campaña el día 2 de Agosto con una rueda de prensa a cargo del presidente de la plataforma Arsenio Domínguez y con las declaraciones de Ismael Serrano y Alejandro Sanz.

Y como envés de la misma moneda, el análisis y desarrollo de la campaña planteados por el Contra-Lobby:

La Plataforma de Nuevos Creadores por la Moda, la Cultura y la Belleza, "Estoy de Moda", presenta su campaña a favor de la moda, como fenómeno cultural, y búsqueda del equilibrio corporal y mental.

La primera está enfocada a un público objetivo joven, que quiere vestir para realzar y traducir su mundo interior. El lema: ¡Estoy de moda!, traduce esta línea haciendo que se corresponda con la parte más explícita de la campaña, pues presenta la moda a través de una perspectiva cultural y como la solución a la búsqueda de identidad de los más jóvenes.

La segunda línea tiene una base más informativa y, por tanto, menos directa. Ésta busca que la belleza se traduzca en equilibrio y que la moda no sea únicamente un atuendo sino un estilo de vida que haga sentirse bien al individuo, por dentro y por fuera. El lema que defiende la vía implícita es: ¡Necesitas equilibrio!

La Plataforma "Estoy de Moda" ha desarrollado una serie de publirreportajes que van a difundirse en semanales de prensa escrita. Entre los títulos se encuentran: "En la belleza, en la salud, en la moda" "Simons, metrosexuales" (sobre las tendencias masculinas) y, además, una serie de noticias para la prensa diaria a cerca de los riesgos de la obesidad y su gasto sanitario. El despliegue de noticias va a ser intensivo entre los meses de Julio y Septiembre, entre los cuales se va a desarrollar la campaña, para crear una conciencia general en tomo al Día Internacional de la Moda, la Cultura y la Belleza, el 1 de Agosto.

Además, la Plataforma concederá una entrevista en exclusivas a los Medios de Comunicación para Masas con motivo del Día Internacional de la Moda, la Cultura y la Belleza, el sábado 1 de Agosto.

PLATAFORMA DE NUEVOS CREADORES POR LA MODA, LA CULTURA y LA BELLEZA: "ESTOY DE MODA" 
La campaña publicitaria que se ha desarrollado desde la Plataforma se divide en cuatro puntos principales: prensa diaria, televisión, radio y publicidad exterior.

\section{En Prensa}

En la campaña gráfica para prensa se han seguido las dos vías indicadas al principio con la que los medios impresos disponen de dos tipos de publicidad.

La primera vía, aquella explícita sobre la moda como elemento para la interpretación del mundo interior, ha sido la más desarrollada por la Plataforma pues pretende ser la vía directa y con mayor posibilidad para llegar a su público objetivo. Esta consiste en presentar durante el primer mes de campaña, julio, un cuadro clásico de la pintura española $\mathrm{y}$, durante los siguientes dos meses que dura la campaña (agosto y septiembre), la versión actualizada de los mismos (mostrando cinco estilos distintos de moda). Estos anuncios gráficos van a estar acompañados del lema "Estoy de Moda", en aquellos en los que solamente aparezca una persona, o "Estamos de Moda" si en el cuadro o foto aparecen más de una persona.

Los cuadros escogidos por la Plataforma son: "Las señoritas de Avignon" (Pablo Ruiz Picasso), "La muchacha en la ventana" (Salvador Dalí), "La Venus del espejo" (Diego Velásquez), "El Quitasol" (Francisco de Goya) y "Carlos III de niño" (Jean Ranc, pintor de la Cámara española de los Borbones). Se ha intentado que cada periódico se identifique, principalmente, con dos de los cuadros seleccionados (a excepción del diario La Razón) y, que en este sentido, publique los viernes el menos asociable al medio y, los domingos, el más representativo de la ideología del periódico (y también el sábado 1 de agosto, Día Internacional de la Moda, la Cultura y la Belleza). Con esto se pretende buscar el equilibrio entre los lectores del medio y el contexto que va a acompañar al anuncio.

\section{En Televisión}

Los anuncios grabados para televisión por la Plataforma son dos y hacen referencia a la vía principal de la campaña, la del lema "Estoy de Moda". Los anuncios audiovisuales recrean la idea de los anuncios gráficos, trasladando cuadros clásicos al día de hoy.

Los cuadros elegidos son "Los Borrachos" de Velázquez y "'La maja desnuda" de Goya. La idea de los anuncios varía desde los gráficos en que en los medios audiovisuales no va a haber dos versiones distintas, sino que se van a intercalar imágenes actuales e imágenes del cuadro en el mismo.

\section{En Radio}

Las cuñas radiofónicas grabadas son cinco. En este medio se ha querido hacer hincapié en la vía "Necesitas Equilibrio" porque la Plataforma ha considerado que es un lema 
mucho más sugestivo para el medio radiofónico (caracterizado por las modulaciones de la voz). Por este motivo, el CD "Cuñas" está compuesto por cinco distintas: las cuatro primeras referentes a la vía "Necesitas Equilibrio" y la última a la vía "Estoy de Moda".

\section{En Publicidad Exterior}

La publicidad exterior está considerada por la Plataforma como primordial, pues no sólo quiere llegar a los públicos objetivos de los distintos medios de comunicación. La Plataforma "Estoy de Moda" quiere estar allí dónde exista la personalidad individual, la moda y el respeto a la salud. Por este motivo cree importante hacer una campaña de publicidad exterior exhaustiva y diversificada en distintos anuncios gráficos.

-Balanza: "Necesitas Equilibrio": se va a utilizar en publicidad exterior de disposición vertical, sobre todo en las marquesinas del suburbano.

-Diseño "Plataforma Estoy de Moda": se va a utilizar en publicidad exterior de disposición vertical sobre todo en las marquesinas del suburbano.

Además por su alegre colorido y por contar con la imagen femenina de la campaña, así como con la dirección de la Plataforma, se ha decidido que va a ser el diseño utilizado para elaborar postales de difusión gratuita, gracias a un convenio con la empresa "Postal Free".

-Diseño "Estoy de Moda" horizontal: este va a ser el anuncio fuerte en publicidad exterior de la campaña. Se pretende que esté presente en todos los sitios posibles: vallas publicitarias, marquesinas, transporte público, cabinas telefónicas, y en definitiva, en todos los espacios posibles pues este diseño engloba la idea general que tiene la Plataforma sobre la moda y cuenta con la imagen femenina de la campaña (actualizando el cuadro de Velázquez de "Las Meninas").

Desde la Plataforma "Estoy de Moda" se han organizado una serie de actos conmemorativos en relación con el Día Internacional de la Moda la Cultura y la Belleza, 1 de agosto.

Uno de los acontecimientos más especiales es el concierto que tendrá lugar el día 1 de agosto en el marco del Fórum de Barcelona, totalmente gratuito. En el concierto participarán los siguientes artistas:

*Carla Bruni; la famosa top-model que ha iniciado su carrera discográfica con un gran éxito en la canción de autor francesa.

*Najwa Nimri; el ejemplo más cosmopolita de nuestro país. La actriz y cantante, de la electrónica más sofisticada, ha dado voz a famosos temas como las Bandas Sonoras de 
las películas "Guerreros", "Asfalto", "Utopía"... y ha protagonizado con gran éxito, películas como "Lucía y el sexo" o "Piedras".

*Marlango; es una banda nueva, surgida en Madrid y que tiene por voz a la también actriz Leonor Watling. Leonor, después de convertirse en chica Almodóvar, ha indagado en la música sorprendiendo gratamente con su jazz-sow al público español y también a todo el mercado nipón.

*Enrique Bunbury; toda una leyenda del rock español. Su aire glam-rock en solitario le convierten en referencia del vanguardismo de España.

*Milla Jovovich; modelo, actriz y cantante. Sorprende a cualquiera en cada nueva faceta que toma por delante. Ha sido chica L' Oreall, ha servido de guerrillera en películas como "Juana de Arco", "El Quinto elemento" o "Resident Evil" y ahora, nos sorprende con un disco lleno de temas electro-folk. La chica de las pestañas extra-largas es mucho más que un cuerpo bonito.

*Goldfrapu; este dúo británico ha sido la revelación en los últimos tiempos en festivales de renombre como el FIB, caracterizados por la elegancia sublime de su electrónica cabaretera. Allison, la cantante, se ha atrevido a hacer la versión de Baccara, "Yes Sir I Can Boggie" con lo que, tratándose de la música oficial de la campaña de la Plataforma, merecen una mención especial y un lugar en este concierto conmemorativo.

*Baccara; uno de los dúos españoles más divertidos e internacionales. Son las que dan voz a la campaña de la Plataforma "Estoy de Moda" y actuarán en último lugar para presentar la canción que se puede escuchar tanto en radio, como en televisión.

Como se puede observar, la variedad es lo que caracteriza a este concierto. Sin embargo, todos los artistas tienen algo en común: la modernidad, la vanguardia y el gusto por la moda y el cuidado de la salud.

Además, con todos ellos se ha grabado un disco que podrá ser retirado gratuitamente en la sede de ¡Estoy de Moda! (Paseo de Gracia, 53. Barcelona). Y a partir del 3 de agosto, este $\mathrm{CD}$ se puede conseguir con la compra de cualquier producto de los patrocinadores oficiales de la campaña.

Este será el acontecimiento central de la campaña pues va a tener una elevada repercusión mediática y un gran aluvión de visitantes. No obstante, la plataforma ha nacido para promover las cualidades de la moda como expresión artística de gran repercusión social y como invitación al cuidado físico, por lo que propone una serie de cursos, seminarios y conferencias para acercar estos propósitos al mayor público posible. La Plataforma se ha acercado a los ámbitos educativos y culturales para llevarlas a cabo, con lo que la organización de los mismos se ha hecho desde la 
Universidad Complutense de Madrid, la Universitat Pompeu Fabra de Barcelona y El Fórum de Barcelona.

Los cursos, seminarios y conferencias, sus fechas, así como quiénes los imparten, se pueden consultar en los folletos que la Plataforma ha elaborado y que serán repartidos en Madrid y Barcelona en mesas informativas que van a instalarse en puntos estratégicos de las ciudades para facilitar la información al ciudadano (además de encontrarse en la página web de la Plataforma).

A parte del CD conmemorativo ya citado anteriormente la Plataforma ha diseñado dos camisetas distintas: una de ellas promociona el Portal Web de la Plataforma (www.voguis.com) y la otra es para la promoción del lema principal de la campaña: "Estoy de Moda".

Esta última se repartirá a todos los participantes de los eventos programados por la Plataforma mientras que la que hace referencia al Portal Web se regalará junto al CD promocional en los establecimientos colaboradores (por tratarse de un diseño más actual y con colores más atrevidos).

Con estos regalos promocionales, la Plataforma pretende crear una imagen actual, cercana y preocupada por su público objetivo.

Por último, es de gran interés hacer referencia a la creación, por parte de la Plataforma (conjuntamente con Canal +) de un Portal Web: www.voguis.com. El cual contiene toda la información referente a la campaña de la Plataforma, los objetivos que persigue, los patrocinadores de la misma, y un largo etcétera que se puede visualizar en el CD Portal Web en el que se incluye una presentación de la misma en Power Point.

¿De parte de quién hubiera inclinado el lector la balanza de su voluntad. Y... siendo sinceros, ¿no ven ciertas reminiscencias de manipulación de la Opinión Pública con los eventos que suceden a nuestro alrededor cotidianamente?

\section{NÍHIL ÓBSTAT . IMPRIMÁTUR}

\section{BIBLIOGRAFIA}

- ABRAHAM, Suzanne y LLEWELLYN-JONES, Derek (1994): Anorexia y bulimia: desórdenes alimentarios. Editorial Alianza. Buenos Aires.

- ÁLVAREZ, Nieves y CINTADO, Lola (2001): Yo vencí la anorexia. Temas de Hoy. Madrid. 
- APOSTOLIDES, Marianne (1999): Vencer la anorexia y la bulimia. Editorial Urano. Barcelona.

- BASSAT, Luis (1993): El libro rojo de la publicidad. Folio. Barcelona.

- BAUXBAUM, Gerda (2007): Iconos de la moda. Sociedad editorial Electa España. Sevilla.

- BRONWYN, Cosgrave (2005): Historia de la moda. Desde Egipto hasta nuestros días. Gustavo Gili, S.A.

- CABETAS HERNÁNDEZ, Isabel (2002): Anorexia nerviosa: la melancolía como sustrato psico-patológico de la enfermedad. Universidad Complutense. Madrid.

- CALVO SAGARDOY, Rosa (2002): Anorexia y bulimia: guía para padres, educadores y terapeutas. Editorial Planeta. Madrid.

- CASTILLO SÁNCHEZ, María Dolores y LEÓN ESPINOSA DE LOS MONTEROS, María Teresa (2005): Trastornos Del Comportamiento Alimentario: Anorexia y bulimia nerviosa. Formación Alcalá. Alcalá de Henares.

- CASTRO FORNIELES, Josefina y TORO, José (2007): Anorexia nerviosa: el peligro de adelgazar. Morales i Torres. Barcelona.

- CERVERA, Montserrat (2005): Riesgo y prevención de la anorexia y la bulimia. Pirámide. Madrid. 
- DAVIS, Fred (1992): Fashion, culture and identity. The university of Chigo Press. Chicago.

- DE SOUSA CONGOSTO, Francisco (2007): Introducción a la historia de la indumentaria en España. Istmo. Málaga.

- FIGUERAS, Josefina (1997): La moda. Sus secretos y su poder. Albacore. Madrid.

- GARCÍA RODRÍGUEZ, Fernando (1993): Las adoradoras de la delgadez: anorexia nerviosa. Díaz de Santos. Madrid.

- GARCÍA WIEDEMANN, Emilio J. (1998): Moda y sociedad. estudios sobre: educación, lenguaje e historia del vestido. Athos- Pergamos.

- GÓMEZ MARTÍNEZ, María Ángeles (2003): ¿Qué Es La Bulimia?. Pirámide. Madrid.

- GORDON, Richard A. (1994): Anorexia y bulimia: anatomía de una epidemia social. Ariel. Buenos Aires.

- GUERRERO, José Antonio (2009): Nuevas Tecnologías Aplicadas a la Moda, Diseño, Producción, Marketing y Comunicación. Parramón. Barcelona.

- HERREROS ARCONADA, Mario (1995): La publicitat. Pòrtic. Barcelona.

- JONES, Sue J. (2005): Diseño de moda. Blume. Madrid. 
- LADISH, Lorraine C. (1994): Me siento gorda: la cara oculta de la belleza: bulimia y anorexia: (una experiencia personal). Editorial Edaf. Madrid.

- LEÓN, José Luis (1996): Los efectos de la publicidad. Ariel. Barcelona.

- MARTÍNEZ-FORNÉS, Santiago (2006): La obsesión por adelgazar: anorexia y bulimia. Espasa-Calpe. Madrid.

- MORANDÉ, Gonzalo (1999): La anorexia: cómo combatir y prevenir el miedo a engordar de las adolescentes. Temas de Hoy. Madrid.

- MORANDÉ, Gonzalo (1995): Un peligro llamado anorexia: la tentación de adelgazar. Temas de Hoy. Madrid.

- OCAÑA, Fernando (1997): Veinte ideas sobre publicidad. Ediciones B. Barcelona.

- RIVIÈRE, Margarita (1998): Crónicas virtuales. Ed. Anagrama. Barcelona.

- RODRÍGUEZ RIEZU, Marta (2009): Coolhunting, marcando tendencias en la moda. Parramon. Barcelona.

- SELVINI PALAZZOLI, M. (1999): Muchachas anoréxicas y bulimicas: la terapia familiar. Paidós. Madrid.

- SIMON, Yves y NEF, François (2005): Cómo Superar La Anorexia. Síntesis. Madrid. 
- TOMÀS, Josep (Ed.) (2001): Psicosomática, bulimia, obesidad y otros trastornos de la conducta en la infancia y la adolescencia. Laertes. Barcelona.

- TOMÀS, Joseph y BASSAS, Núria (1999): Anorexia y otras alteraciones de la conducta en la infancia y adolescencia. Editorial Laertes. Barcelona.

- TORO, Josep (1996): El cuerpo como delito: anorexia, bulimia, cultura y sociedad. Ariel. Buenos Aires.

- TORO, Josep y ARTIGAS, Mónica (2001): El cuerpo como enemigo: comprender la anorexia. Martínez Roca. Madrid.

- TOUSSAINT-SAMAT, Maguelonne (1994): Historia técnica y moral del vestido. Alianza editorial. Madrid.

- TURÓN GIL, Vicente José (1997): Trastornos de la alimentación: guía básica de tratamiento en anorexia y bulimia. Masson. Barcelona. 